\title{
Dental hygienists - a post qualification survey
}

\author{
A survey of hygienists qualifying from the Liverpool School of Dental Hygiene 1977-1998 by D. G. Hillam \\ Br Dent J 2000; 188: 150-153
}

\section{Objectives}

To analyse the working patterns of all those who qualified from the Liverpool School of Dental Hygiene over a 20 -year period. To assess the proportion who give up practice, the degree of parttime work, career breaks, job satisfaction, availability of continuing professional education etc.

\section{Method}

A questionnaire sent to all 226 hygienists who qualified from the School between 1997 and 1998, whether still enrolled as dental hygienists or not.

\section{Results}

Responses were received from $83 \%$ of whom $89 \%$ were still working as hygienists, the majority in general practice. $46 \%$ had taken an employment break, mostly for maternity reasons but a significant number for other reasons. Around $80 \%$ expressed good job satisfaction. Although there is a high level of part-time work, especially after career breaks, few had experienced difficulty in finding employment. One third of respondents considered that the availability of continuing professional education was 'poor' or 'very poor'.

\section{Conclusions}

The great majority of hygienists enjoy good job satisfaction and work in more than one general dental practice.

Comparisons suggest that they continue to work in their chosen career at least as much as female dentists do in theirs. The reasons for this are thought to be that hygienists tend to be recruited from the ranks of highly motivated, mature dental nurses and that the profession lends itself to part-time work which can be combined with family commitments. There are perceived deficiencies in the availability of continuing professional education, which may be remedied by the development of distance learning packages and Section 63 type courses designed specifically for them.

\section{Comment}

As the delivery of dental care focuses more on a team approach, this paper is timely and reports on the career patterns of dental hygienists who have qualified from the Liverpool School of Dental Hygiene over a 20 -year period. The point is made in the introduction that the dental hygienist training schools not only have a responsibility to monitor methods of recruitment so that students accepted onto the course complete it, but also when qualified they have the aptitude and motivation to work in their chosen profession for a substantial time afterwards. It is a fact that the vast majority of applications to UK schools of dental hygiene are from females who predominately have a dental nurse background. Few males apply for this course even though direct entry avoiding dental nurse training is possible for those with two A level passes.

The aim of the survey which involved more than 200 hygienists, was to assess if there had been a return to work by dental hygienists after a break caused by family commitments, to assess job opportunities, access to continuing education and the current level of job satisfaction. This is timely because the numbers of dental hygienists qualifying each year falls short of the needs of the country as a whole, so the importance of returners to work is paramount. Reassuringly we see that $89 \%$ of dental hygienists qualifying from Liverpool still work as hygienists but of these $74 \%$ had a career break for maternity and family reasons, although we do not know the average length of time involved as it was stated as 3 months or more. Fortunately, job satisfaction often expressed as low did appear to be high in this group. This is again reassuring and with additional duties around the corner should be even higher in the future.

Access to continuing professional development (CPD) was variable with nearly half saying that it was good or very good and a third saying it was bad or very bad. This is an area which does need to be addressed, particularly as continuing professional development for hygienists is now a requirement by the GDC. ${ }^{1}$ In addition, if dental hygienists are being asked to undertake more clinical duties then an investment for CPD from central funds would seem to be appropriate.

One concern highlighted is the tendency for hygienists, once they have had a career break for whatever reason, to rarely go back to work full time. The career break also tends to lead to a loss of confidence if it is protracted, and to overcome this hygienists sensibly try to arrange refresher courses but this can often be difficult. This is frequently due to them being geographically distant from a dental hygiene school who would usually provide the update course.

Finally, it could be that some of the responses to this survey indicate a need to attract more males into the profession particularly as there are currently 4,085 enrolled hygienists of which only 84 are male. ${ }^{2}$ This is obviously an area for further debate as hygienists (and other PCDs) become more important in the dental team and more involved in the treatment of patients.

1 Guidance to Dental Hygienists and Dental Therapists, Maintaining Standards. General Dental Council, September 1999.

2 Personal Communication, Registration Department, General Dental Council

\section{K H Figures}

Director of the School of Dental Hygiene and Dental Therapy, Sheffield 